NOTAS Y DISCUSIONES

\title{
Retórica, argumentación y derecho
}

\author{
JUAN ANTONIO GARCIAA AMADO \\ Universidad de León
}

\section{Introducción}

Para comprender el papel que en la actual teoría jurídica juega o puede jugar la retórica y para situar el origen de las llamadas teorías de la argumentación jurídica conviene comenzar con unas breves consideraciones sobre la situación anterior de la teoría del derecho y de su interpretación y aplicación.

Es de sobra conocido que la importancia que a la retórica y la tópica se otorgaba entre los juristas medievales, tanto en el modo "polémico» de concebir la búsqueda de las soluciones para los litigios como en el método de enseñanza del derecho, entra en crisis con el racionalismo de la época moderna y el cambio en el modelo ideal de racionalidad. El viejo arte de la prudencia es reemplazado por la pretensión de dotar al razonamiento jurídico ( $\mathrm{y}$ al moral) de un grado de certeza y coherencia parangonable al de la matemática o las ciencias naturales. Baste pensar en el rotundo ataque de Kant a la retórica. El iusnaturalismo racionalista pretende construir sistemas completos de derecho natural cuyos preceptos se ordenan jerárquicamente según su grado de generalidad y entre los cuales se da una relación deductiva. Se confía en la capacidad de la razón para captar evidencias ínsitas en la propia naturaleza humana y para traducirlas a normas. Ese derecho natural modemo supone, pues, postular un derecho de la razón capaz de ofrecer respuestas indubitadas, y al legislador y la ley positiva se deja sólo la misión de concretar y adecuar a las particulares circunstancias sociales esos supremos mandatos racionales. La certeza en el conocimiento y el modo de concebir el razonamiento práctico como sustancialmente tasado y predeterminado en su desarrollo dejan poco sitio a la discusión de lo meramente opinable. El conocer sustituye al decidir y la ciencia a la retórica o la prudencia.

Como tantas veces se ha dicho, el movimiento codificador que se extiende desde fines del siglo xvIII supone la traslación de esos esquemas y pretensiones al ámbito del Derecho positivo, del Derecho legislado. Opera el llamado mito del legislador racional y en los códigos legales se ve la plasmación, ahora bajo la forma de ley positiva, escrita, de una omnisciencia del legislador que le permite conocer las necesidades sociales y su mejor solución, y de una omnipotencia que le posibilita imponer ese conocimiento verdadero como mandato incuestionable. $Y$ nuevamente quedan sin sitio la discusión, el artificio retórico y el debate en torno a lo dudoso. El sistema jurídico, ahora puramente positivo, se entiende como coherente, es decir, carente de antinomias, y completo, esto es, carente de lagunas. El juez encuentra en la ley perfectamente prefijada y pre- 
determinada la respuesta a cualyuicr litigio que tenga que resolver, su papel se limita al de ser «boca que pronuncia las palabras de la ley», según la tan manida fórmula de Montesquieu. El razonamiento jurídico, el razonamiento del aplicador del derecho, se explica como un puro silogismo, en el que la ley forma la premisa mayor, los hechos que se juzgan la premisa menor y la sentencia se sigue con necesidad lógica como pura conclusión. Se suele denominar esta visión como teoría de la subsunción, resaltando que el juez se limita a subsumir el hecho concreto bajo el supuesto de hecho abstracto de la norma, aplicándole la consecuencia en ésta prevista cuando tal encaje de lo concreto bajo lo abstracto acontezca.

El problema del lenguaje no podía dejar de estar presente de todas formas. En los primeros códigos europeos, a fines del xviI, se contenían normas prohibitivas de la interpretación, en la confianza de que las palabras de legislador eran plenamente claras y precisas y desconfiando fuertemente de la manipulación de la norma que el juez pudiera llevar a cabo por vía interpretativa. No obstante, este que podríamos denominar mito de la claridad de la ley pronto se mostró inviable. Sin embargo, la teoría del derecho disponía de medios para solventar el problema de la interpretación sin pérdida de la seguridad, al menos aparentemente. La clave aquí estará en los llamados cánones de la interpretación, que en su forma "canónica" expondrá Savigny en las primeras décadas del xix. Cuatro eran para Savigny dichos cánones: gramatical, lógico, histórico y sistemático. Savigny pensaba que la utilización conjunta de estos cuatro criterios permitiría en todo caso al intérprete hallar la idea inmanente a la ley, averiguar el pensamiento que en ella plasmó el legislador. La interpretación de los términos de la ley es necesaria, sí, pero existe ese «método» que permite que el juez pueda interpretar con plena objetividad y certeza, sin margen para sus valoraciones personales y para la arbitrariedad. Existe un cauce para convertir el significado dudoso en significado cierto.

Curiosamente, esa visión del derecho y del razonamiento jurídico se impone en dos ámbitos cuya situación jurídica era bien diversa, en Alemania y en Francia. En Francia se promulga en 1804 el Código Civil, el famoso Código de Napoleón, y a partir de él se impondrá a lo largo de todo el siglo xix la llamada Escuela de la Exégesis, En el Código estarian todas las respuestas, y la actividad del juez y del profesor de derecho dcberá ser puramente exegética, fiel a la letra, plenamente respetuosa del sentido, casi siempre claro, de los preceptos. Y en caso de duda y de que se plantec un problema interpretativo, se da total prevalencia a la averiguación de la voluntad auténtica del legislador. Por detrás de la letra de la ley hay una voluntad que la ilumina sin margen para la incertidumbre. Ese positivismo estatista y logicista se tiñe en Alemanja de ontologismo. En los Estados alemanes no existe un Código Civil (el BGB, Código Civil alemăn, entra en vigor en 1900), sino que el derecho es el derecho romano de la recepción, el derecho de Pandectas, hibridado con elementos de derecho común y con una fuerte impronta de reelaboración doctrinal. El lugar que en el razonamiento jurídico ocupa la pura ley positiva en el caso francés lo ocupan en Alemania los conceptos jurídicos. La doctrina plenamente dominante se llamará allí Jurisprudencia de Conceptos. Por detrás de las normas jurídicas existiria todo un entramado sistemático de conceptos que son expresión de una especie de razón jurídica universal que habría tenido su mejor plasmación y reflejo en el derecho romano. Nociones como negocio jurídico, testamento, contrato, compraventa, préstamo, etc., no serían puros nombres de coyunturales invenciones de un legislador, sino realidades ontológicas poco menos que intemporales, con 
su legalidad inmanente y con capacidad para combinarse y reproducirse dando solución a cualquier conflicto. La subsunción aquí es inmediatamente subsunción bajo la norma, pero mediatamente y en última instancia subsunción bajo los conceptos. Esos conceptos forman un perfecto sistema que tiene su cúspide en la idea de autonomía de la voluntad. El manejo de los conceptos, así entendidos, no es aná “ lisis de categorías lingüísticas, sino averiguación de esencias. La interpretación jurídica, por tanto, se mueve entre la dogmática y una filosofía que se pretende positiva a partir de un apriorismo ontológico que ve realidades plenas en esencias ideales.

Todo ese planteamiento entra en crisis con el cambio de siglo. En Alemania, Jhering, primeramente defensor radical de la Jurisprudencia de Conceptos, insistirá ya algunas décadas antes en que el derecho no es un puro sistema de conceptos, sino vida social e historia, y que sólo desde las necesidades sociales puede entenderse $y$ aplicarse, de modo que lo que importa si se quiere interpretar y aplicar correcta. mente la norma es el fin al que ésta sirve. En Francia, Geny distinguirá entre lo dado y lo construido en el derecho, resaltando que la norma legal no agota el derecho ni predetermina plenamente la sentencia, con lo que queda siempre un amplio espacio para la valoración. No podemos aquí paramos demasiado en estas cuestiones. Importa resaltar solamente que en las primeras décadas del siglo $\mathrm{xx}$ se asiste ya a un auténtico cambio de paradigma en la teoría y metodología jurídicas. Pasan a ser lugar común afirmaciones que hoy en día se tienen por indiscutibles, pero que en su origen suponen una verdadera ruptura con el pensamiento anterior: el ordenamiento jurídico positivo posee antinomias y, sobre todo, está lleno de lagunas. El legislador no pudo preverlo y regularlo todo, a lo que se suma que las sociedades cambian y surgen nuevas necesidades $y$ situaciones que piden nuevas respuestas que en el código no se encuentran, o resulta injusto e inadecuado aplicar en todas las circunstancias la solución legal al pie de la letra. Más relevante aún para nuestro tema resulta la siguiente constatación, que desde esta época se impone: los cánones de la interpretación, en su pluralidad y diversidad (la doctrina había añadido a los cuatro de Savigny el canon o criterio teleológíco) no conducen a una interpretación única, sirven para justificar interpretaciones y, consiguientemente, decisiones distintas y contrapuestas. Bajo este prisma, interpretar ya no es tanto conocer o averiguar cuanto valorar y decidir. El referente de la sentencia correcta ya no lo proporciona un método de interpretación, sino que se busca, cuando se cree que es posible hallar alguno, en criterios sociológicos o de justicia.

Tal vez es curioso que en esa situación no se hablara de retórica aun cuando el componente retórico del razonamiento jurídico y de los criterios de interpretación comienza a quedar bien de relieve. Si los criterios usuales de interpretación no son más que instrumentos de que el jurista puede valerse para presentar o motivar, bajo una apariencia de objetividad y tecnicismo, lo que no son más que opciones subjetivas guiadas por intereses o valores, parece claro que conviene abordar el discurso jurídico atendiendo a los medios argumentativos de que se vale y resaltando su dimensión más «lingüística» que puramente técrica o específicamente «jurídica». Este paso, sin embargo, no se dará, como veremos, hasta la segunda mitad de siglo. En la época a la que nos estamos refiriendo la doctrina se preocupara más bien de buscar claves decisorias materiales más allá de la ley o complementarias de ésta, apelando a la consideración de la justicia del caso, de las necesidades e intereses sociales, del sentir popular, etc. O se refugiará, en otros casos, en un escepticismo y relativismo que trate de salvar una ciencia jurídica sociológica, psicológica o pura- 
mente normativa, pero ya no apta para imponer a la praxis jurídica ningún género de racionalidad. Tracemos un muy elemental esquema, aunque sólo sea a efectos de comprender el contexto y las razones de la posterior emergencia de los enfoques retóricos.

Podriamos, muy elementalmente, cłasificar las doctrinas de las primeras décadas del siglo sobre estos temas en racionalistas e irracionalistas. Irracionalistas serían aquellas que no creen que ningún método o procedimiento pueda dotar de garantías de racionalidad a la decisión juridica, que sería antes que nada una decisión guiada por las valoraciones e inclinaciones del juez. Podríamos encajar en este apartado, $\sin$ muchos matices, al movimiento de derecho librc, al realismo juridico o a Kelsen. El movimiento de derecho libre, con autores como Kantorowicz, Fuchs o Ehrlich, sitúa como clave de la decisión lo que llama el ssentimiento jurídicos (Rechtsgefühl) del juez, sentimiento en última instancia incontrolable, pero en alguna medida educable. Recomiendan abandonar la hipocresía de una teoría que trata de presentar al juez como puro autómata perfectamente objetivo, acrecentando con ello la irresponsabilidad por decisiones que tienen un altísimo componente personal, y proporcionar al juez una amplia formación cconómica, sociológica y ćtica que le permita comprender la auténtica entidad de los conflictos que dirime y poner sus valoraciones en sintonía con lo que la sociedad demanda. Propugnan un Ienguaje jurídico que huya de tecnicismos y de especulaciones conceptualistas y que permita una cabal comprensión de las normas y su sentido, dejando el menor espacio posible para subterfugios interpretativos que encubren un puro decisionismo.

El realismo jurídico parte de un positivismo empirista que conduce a ver en el derecho meros fenómenos sociológicos y psicológicos, y a descreer de cualquier posibilidad de que puedan existir patrones de racionalidad para las valoraciones subjelivas a que toda interpretación y decisión en derecho se remiten. Esto lleva a autores como Alf Ross a rechazar por inútil cualquier metodología jurídica normativa o prescriptiva y a insistir en la única utilidad de una metodología jurídica descriptiva. Ésta analizaría los modos en que los jueces deciden los casos, los criterios interpretativos que suelen usar, la ideología que se trasluce de sus decisiones, el modo en que motivan sus sentencias, etc., y todo ello con la única finalidad de hacer previsibles, hasta donde sea posible, sus decisiones en casós futuros. Para el realismo no hay más derecho que el derecho judicial, y la ley sólo cuenta en la medida en que el juez crea que debe aplicarla y en que condicione de hecho sus sentencias. Los realistas recalcaron especialmente la idea de que el juez primero decide y luego motiva, con lo que la motivación expresa de la sentencia no es más que el revestimiento con el que la pura decisión se disfraza de objetividad. Curiosamente, se abría nuevamente por ahí un análisis en clave retórica que los realistas no hicieron.

En cuanto a Hans Kelsen, seguramente el más influyente jurista de este siglo, comparte con el realismo ese escepticismo en cuanto a la racionalidad de las decisiones, pero trata de salvar la posibilidad de una ciencia jurídica que ya no seria, como en el realismo, una ciencia empírica, sino una ciencia normativa. Kelsen arranca del postulado de la separación cntre ser y deber, Sein y Sollen, y mantiene que si una norma es jurídica es porque tiene en su ser algo que la especifica frente al puro mandato, frente al acto de voluntad que la genera o el sentimiento psicológico que en sus destinatarios suscita. Ese algo más es un particular «sentido», una impronta que se traduce en lo que se denomina «validez». La validez de una norma jurídica provicne sicmpre, según Kelsen, no de un hecho, sino de otra norma, concretamente de que cada norma válida lo sea porque ha sido 
creada con arreglo a una habilitación y un procedimiento establecidos en una norma superior del mismo sistema. En Kelsen es fundamental la distinción entre norma juridica (Rechsnorm) y proposición jurídica (Rechtssatz). Las normas jurídicas no son verdaderas of falsas, sino válidas o inválidas, pero las proposiciones jurídicas sí pueden calificarse en términos de verdad o falsedad. La cicncia jurídica realiza afirmaciones acerca de normas y de sus interpretaciones posibles, es puramente descriptiva y sólo se mantiene como ciencia en la medida en que describa sin valorar. Cuando el científico del derecho interpreta una norma se limita a poner de manifiesto sus posibles significados, pero no optará por ninguno de ellos como el mejor o más conveniente. En cambio, el juez sí ha de dar ese paso, puesto que ha de decidir en todo caso, y esa valoración que determina la opción por una interpretación y la sentencia es lo que hace que el trabajo jurídico práctico no pueda tener carácter científico.

Con estos últimos datos nos hemos alejado del hilo central de nuestra argumentación, que debe llevarnos a la retórica. Pero esa lejania no es total, pues tiene que ver con cuestiones que sí conectan con cuestiones relacionadas con la teoría del lenguaje y con el surgimiento de la retórica jurídica como doctrina. Piénsese en lo mucho que el asunto tiene que ver con la posibilidad de elaborar o no una lógica jurídica, en su doble dimensión de lógica de las normas y de lógica del razonamiento jurídico. El ver las normas como enunciados a como mandatos, el entender que pueden o no ser aplicables a ellas las categorías de verdadero o falso enlaza con la posibilidad de construir o no una lógica jurídica y de que sea aplicable la lógica proposicional, o tenga que diseñarse una especifica lógica deóntica. $\mathbf{E}$ igualmente podemos ver todo esto desde el punto de vista de una posible clasificación de las concepciones de la norma según que hagan mayor hincapié en la dimensión sintáctica, semántica o pragmática del lenguaje o discurso jurídico. Por poner un ejemplo en el que no podemos pararnos más, piénsese en las distintas implicaciones de las dos visiones de las normas que como alternativas plantean Alchourrón y Bulygin: la concepción hilética, según la cual las normas serian el significado de enunciados normativos, y la expresiva, para la que serían el resultado del uso prescriptivo del lenguaje.

En la metodología jurídica de este siglo el punto de vista que podríamos llamar «ortodoxo» lo mantienen las corrientes racionalistas, que asumiendo el componente de libertad decisoria de la praxis juridica piensan que es posible ofrecerle al juez pautas metódicas que permitan que su interpretación de los términso legales sea la correcta y objetiva. La línea evolutiva ahí pasa por la jurisprudencia teleológica, la jurisprudencia de intereses y la jurisprudencia de valoraciones. La primera da prioridad a la consideración del fin en la interpretación y aplicación del derecho. La segunda destaca que el fin de toda norma jurídica es solventar un conflicto de intereses y que el intérprete ha de tener presente la indole de ese conflicto y de tales intereses para calar en el significado de la norma y aplicarla adecuadamente, concretando ante cada caso la opción de fondo que el legislador tomó en ese conflicto. La jurisprudencia de valoraciones pone de manifiesto que esa opción del legislador obedece a un sistema de valores que en el ordenamiento juridico se plasma y en el que el juez ha de insertarse para que su decisión refleje los parámetros de fondo del ordenamiento y no sus personales opciones. La lectura de la ley vuelve ahí a ser una lectura «guiada» por pautas hermenéuticas que se pretenden claras. Nuevamente queda poco sitio para retóricas.

Se puede afirmar que el renacer del interés por la retórica entre los juristas responde a un planteamicnto realista (irracionalista) y al intento de superarlo por 
nuevas vias, muy distintas de las de las posturas racionalistas que acabamos de presentar. Hay ahi una curiosa evolución hasta llegar a las actuales teorias de la argumentación juridica, que al menos en sus planteamientos más representativos e influyentes se proponen un análisis del discurso jurídico que permita extraer reglas de su racionalidad que son reglas del argumentar, criterios retóricos que, al mismo tiempo, liberen a la retórica de su pura instrumentalidad y conviertan una actividad jurídica, entendida como básicamente argumentativa, en actividad que pueda tildarse de racional. Trataremos de mostrar esto con algún detenimiento. Pero aunque sea como anécdota significativa merece resaltarse que algunos de los más influyentes precursores de esas teorías de la argumentación e iniciadores de los planteamientos tópicos y retóricos comenzaron su andadura teórica como cultivadores de la lógica y desembocaron en la tópica y la retórica de resultas de su escepticismo frente a la posibilidad o la utilidad de una lógica jurídica formal, especialmente de una lógica del razonamiento jurídico. Es el caso de Theodor Viehweg y de Chaim Perelman.

Las teorías de la argumentación jurídica, con Perelman a la cabeza, vendrán a buscar una vía media entre el irracionalismo metodológico de los unos y el optimismo cientificista de los otros ${ }^{j}$. Desde los años cincuenta la situación de crisis de la metodologia jurídica va a motivar una serie de respuestas estrechamente emparentadas por compartir una idea fundamental: que la demostración meramente lógica y la prueba empírica no son ciertamente aplicables al trabajo valorativo con el derecho, pero que ello no implica que la aplicación del derecho sea una operación perfectamente arbitraria y aleatoria, pues poseeria su propia racionalidad. Pero esta racionalidad, que el derecho compartiria con otras disciplinas pertenecientes al ámbito de la acción o la razón práctica, sería de un género especial: sería racionalidad práctica. Se anticipa así, en estrecha referencia al derecho y su problemática metodológica, lo que la filosofía general celebrará años más tarde como «rehabilitación de la razón práctica».

En esos años surgen varias doctrinas con esa común orientación. Perelman rescatará la retórica aristotélica para mostrar la racionalidad argumentativa del razonamiento jurídico y elaborar su teoría de la argumentación; Viehweg acudirá también a la tradición para rescatar la tópica y mostrar el carácter tópico del razonamiento orientado a la justificación de la acción; Recaséns Siches creará el concepto de «logos de lo razonable» para expresar el tipo de racionalidad que preside esos campos, y en el ámbito de la filosofía, pero tomando al derecho como campo de aplicación prototipico, Toulmin mostrará que también en el razonamiento práctico se contienen furdamentaciones y que también en el razonamiento empírico o analítico se interrumpe en algún punto la cadena de explicaciones o justificaciones de las premisas, con lo que desaparece la diferencia radical en cuanto a la racionalidad de ambos razonamientos.

Se ponen así las bases de lo que se llamará, grosso modo, teorías de la argumentación jurídica, y que suponen en realidad un nuevo paradigma para la metodología jurídica y la filosofía del derecho en general. Pero lo anterior no significa que las doctrinas que acabo de mencionar sean idénticas en sus planteamientos o sus propósitos, mâs allá de esa su común condición de precursoras o iniciadoras del nuevo paradigma. Asi, mientras Perelman dedica su obra fundamental a la descripción del tipo de recursos argumentativos utilizables para alcanzar en estas materias la adhesión del auditorio correspondiente, Toulmin desarrolla el esquema formal de la argumentación, y Viehweg intenta mostrar la técnica de la invención o hallazgo de argumentos. 
Asistimos así al comienzo de un cierto cambio de paradigma que en nuestros días va camino de consolidarse. Ese cambio supone el paso de entender el razonamiento jurídico como monológico a verlo como esencialmente dialógico. No es casual, pues, que en nuestros dias haya caído en desuso la expresión srazonamiento jurídicos y en su lugar se hable de «argumentación jurídica». La práctica jurídica decisoria no está primariamente presidida por un razonar subjetivo, sino por un argumentar intersubjetivo. Las razones que cuentan no son las de la razón individual, las de la concicncia subjetiva del intérprete y/o juez, sino los argumentos intersubjetivos, las razones que se expresan hacia los otros como justificación de las opciones y decisiones. De estc modo, la "verdad" jurídica no se averigua subjetivamente, se construye intersubjetivamente; no se demuestra en su certeza inmanente, sino que se justifica o se fundamenta en su "razonabilidad» hacia el exterior, para los demás. La corrección de las decisiones no proviene de su correspondencia con una norma que se asimila a un objeto preestablecido, sino que se apoya en el consenso que ante cada caso concreta los perfiles de la norma mediante argumentos que ya no se extraen de la norma misma, sino de postulados socialmente compartidos. Por consiguiente, se abre todo un campo para un tipo de investigación en el que la conexión con la retórica es bien patente: importa averiguar cómo se argumenta en las disputas jurídicas y en la motivación de las decisiones, de dónde se extraen los argumentos, cuáles son sus tipos y su diversa incidencia sobre el correspondiente auditorio, y qué posibilidades hay de distinguir entre la pura manipulación mediante instrumen. tos retóricos y una argumentación jurídica intersubjetiva en la que la construcción discursiva, dialógica, de las tesis no suponga la renuncia a la pretensión de racionalidad.

\section{La tópica jurídica de Theodor Viehweg}

A diferencia de Perelman, Viehweg y sus seguidores no otorgan una relevancia central al problema de la racionalidad de la decisión final y de las valoraciones que la sustentan. Por eso se ha podido afirmar que en cuanto doctrina metodológica, $y$ en comparación con las contemporáneas teorías de la argumentación jurídica, la tópica jurídica es incompleta. No es la racionaliad de los argumentos lo que principalmente preocupa a Viehweg, sino el modo como la pluralidad de argumentos utilizables para cada caso se obtienen y se legitiman socialmente como igualmente válidos en tanto que propuestas de solución para el mismo. Y un discipulo de Viehweg, como es Ballweg, llegară a sostener que la única racionalidad que cabe en la argumentación juridica es de carácter funcional o sistémico, no de indole normativa como la que parecen querer acotar las teorias de la argumentación, por lo que la tópica no pretendería encauzar la formación de un consenso racional ni ser su doctrina, sino únicamente servir de base analítica para la obtención y descripción del consenso posible, sometido a todo tipo de condicionamientos contextuales ${ }^{2}$.

Para Viehweg, el trabajo práctico con el derecho tiene una naturaleza tópica, pues en él la búsqueda de solución para un problema práctico es determinante, y tal solución no es aportada de modo inequívoco por ningún género de sistema. Por mucho que Ios ordenamientos jurídicos traten de ordenarse sistemáticamente sus contenidos no serán producto originariamente de la necesidad lógica, sino de la opción entre premisas posibles, y la interpretación y aplicación de esos contenidos elevados a normas estará determinada también por una scrie de opciones y decisiones, ya que las normas no se pueden formular en un lenguaje formal e inequívoco, existen lagunas, etc. En suma, el trabajo del jurista estaría presidido por la que 
llama Viehweg «aporía fundamental» de la disciplina jurídica: la cuestión de saber qué sea lo justo aquí y ahora, para cada caso $^{3}$. Y por eso le será de particular utilidad la tốpica, entendida como stécnica del pensamiento de problemas" ${ }^{4}$.

La tópica sería aquella disciplina que proporciona los tópicos o argumentos de que el jurista o cada parte en un litigio jurídico pueden echar mano para justificar la decisión tomada o propuesta. Los tópicos serían premisas posibles e igualmente vălidas para el razonamiento jurídico en cada caso práctico. Ante cada problema se podrá defender una $\mathrm{u}$ otra decisión mediante todo un conglomerado de argumentos admisibles y que resultan aceptables entre los juristas de cada momento, tanto en sí mismos, como argumentos utilizables en derecho, como en su aplicación al caso concreto que se discuta. Esos tópicos o argumentos podrán ser de muy diverso tipo, desde principios del derecho a brocardos o dichos jurídicos, lugares comunes, evidencias sociales compartidas, precedentes, postulados de justicia, las mismas normas jurídicas, etc. ${ }^{5}$.

Pero lo que Viehweg ante todo quiere destacar es la prioridad de la inventio o hallazgo de los argumentos o premisas del razonamiento juridico frente al acto mecánico o puramente formal de la conclusio o deducción de la decisión a partir de esas premisas previamente establecidas. $Y$ la tópica sería, ars inveniendi, la técnica de pensamiento que enseña a hallar esos argumentos que son útiles en la justificación dc decisiones por gozar de consenso en el conjunto social o en la comunidad de los juristas.

Para la tópica jurídica la solución decisoria de cada problema jurídico se seguirá a partir de la búsqueda y discusión de los tópicos aplicables. Y de entre el arsenal de tópicos o argumentos que la tópica proporciona serán invocables en cada caso aquellos que resulten adecuados y admisibles en relación con el asunto de que se trate, sin que la decisión en favor de uno $u$ otro como preferente se derive de ningún tipo de jerarquía entre ellos. Pero con esto llegamos al problema clave que las teorías de la argumentación tratan de responder: la cuestión de si la decisión final, la opción de dar preferencia a uno u otro de los argumentos o tópicos en litigio $y$, con ello, decidir en uno u otro sentido dentro de los posibles, es susceptible de control racional; se trataría de averiguar si es posible indicar algún criterio que permita discernir cuâl de entre las decisiones posibles, cuál de los argumentos o valoraciones en pugna es más racional, o si, por el contrario, no hay más instancia de decisión y control que la subjetividad del juez. $Y$ aquí es donde la tópica jurídica se queda en una fase previa a las teorías normativas de la argumentación y donde sus ambiciones teóricas se muestran menores que las de Perelman.

Viehweg no propone el consenso como criterio legitimador o asegurador de la decisión jurídica, ni siquiera un consenso ideal a modo de referente o patrón último. El consenso deberá estar en el punto de partida de la argumentación, respaldando los argumentos utilizables. Sólo servirá como tópico o argumento en la justificación de una decisión o propuesta de decisión lo que goce del consenso de todos, de la mayoría o de los más doctos. Pero puesto que son plurales los tópicos o argumentos enfrentados ante cada problema a resolver, y puesto que la decisión final supone dar preferencia a alguno o algunos de esos argumentos enfrentados e igualmente basados en el consenso, la racionalidad de la decisión final ya no se teoriza en la tópica jurídica. La tópica como método no ofrecería un criterio para la elección entre los tópicos invocados en la discusión ". En este sentido, la de Viehweg sería una doctrina menos ambiciosa que la de Perelman, pero también se podría alegar que es con ello menos idealista y permanece más vinculada a los caracteres de la 
práctica real. En la tópica jurídica el componente descriptivo o analítico prevalecería más claramente sobre el componente normativo, sin dar lugar a esa dificil dualidad presente en el pensamiento de Perelman. De ahí que se haya podido decir también que la tópica jurídica no constituye una auténtica o suficiente teoría de la argumentación jurídica ${ }^{7}$, especialmente si por tal entendemos la teoría normativa de la argumentación. Sc quedaría cn un primer estadio, describiría únicamente los primeros pasos o el punto de arranque del proceso argumentativo que desemboca en la decisión. Sería, en palabras de Mengoni, un medio de selección de "hipótesis de solución" $"$, no un medio de justificación de la opción final por una de esas hipótesis. Lo que Viehweg anticipa, cn la misma ćpoca que Perelman y otros autores, es la idea de que es en el contexto de cada situación donde a través del intercambio de razones sc poncn las bases para que la decisión sea socialmente aceptable, si bien esa aceptabilidad provendrá meramente del consenso que respalda los tópicos en presencia y aun no del procedimicnto de su manejo.

\section{La nueva retónica de Chaim Perelman}

Desde el principio de su obra Perelman es consciente de la parte de opción valorativa que subyace a toda aplicación del derecho y a cualquier consideración del ordenamiento o de sus normas en términos de justicia. Sólo que en su etapa inicial, que tiene su máxima expresión en su $D e$ la justice, de 1945, piensa, en clave de epistemología positivista, que acerca de valoraciones y sistemas de valores no cabe ningún patrón objetivo de racionalidad, por lo que todos serán en todo caso mera man:festación de la subjetividad de quien los afirma. Según Perelman, «no hay valor que no sea lógicamente arbitrario» 9 , «puesto que no hay reglas susceptibles de proporcjonar una solución definitiva al problema de la buena elección, cada elección constituye un riesgo, una opción que afecta a la responsabilidad del hombre que ha optado» ${ }^{10}$. No obstante, y dado ese inevitable componente decisorio, en una segunda etapa trata Perelman de ir más allá de esa postura relativista y busca la forma de dotar de justificación racional a las opciones por unos sistemas de valores frente a otros. La primera conclusión al respecto seguirá siendo que es imposible encontrar para tal fin principios incontestables. Pero se tratará de elaborar una slógica de los juicios de valor» "a partir de un examen detallado de la manera como los hombres razonan efectivamente sobre los valores 11 .

La idea clave para la nueva doctrina perelmaninana estará en los conceptos de decisión y juicio de valor ${ }^{12}$, y la retórica ocupará precisamente ese puesto de «lógica de los juicios de valor».

Pero el elemento decisorio estaba claro ya en su anterior etapa, y lo que en este segundo momento trata Perelman de poner de manifiesto es que las decisiones valorativas no acontecen al margen de toda regla o toda pauta racional. Esa su lógica especifica mostraría precisamente su peculiar racionalidad, distinta pero no inferior de la que preside los razonamientos puramente lógicos o empíricos. Como expresamente dice, «en derecho ningín poder se puede ejercer de manera arbitraria, es decir, no razonable» ${ }^{13}$. Todo lo más cabe una distinción conceptual que reserve el calificativo de racional para las conclusiones de la lógica o la ciencia empírica, conclusiones enjuiciables en términos absolutos de verdad o falsedad, pero que no oponga sin más a esa racionalidad la irracionalidad, sino otro tipo de ejercicio racional que Perelman denomina urazonabilidad». "Lo razonable está ligado al sentido común, a lo que es aceptable en una comunidad dada», no a la idea de verdad, por lo que mientras en ciencia sólo una de las tesis en litigio para explicar un 
fenómeno puede ser verdadera, en materias como el derecho varias propuestas de solución valorativa pueden aparecer como igualmente razonables ${ }^{14}$. Únicamente es no razonable «lo que es inadmisible en una comunidad en un momento dado" ${ }^{15}$, «lo que la opinión común no puede aceptar, lo que percibe como manifiestamente inadecuado a la situación o contrario a la equidad» ${ }^{16}$. Y ahora Perelman dirá que ken filosofía el irracionalismo se explica fundamentalmente por el desconocimiento de la racionalidad de los procesos de justificación ${ }^{17}$.

De este modo, Perelman ataca el «absolutismo de la razón» presente en el iusnaturalismo o en la doctrina del legislador racional, tal como la presuponía la metodología jurídica tradicional, sin caer por ello en la proclamación del irracionalismo ${ }^{18}$. Es posible un control y una crítica de las decisiones jurídicas y de las valoraciones que les subyacen en términos de razón, y tal control lo llevarán a cabo los jueces. A ellos les corresponde dejar patente que sus decisiones no son fruto de su libre arbitrio, sino que se pueden justificar como razonables y acordes con lo que la correspondiente sociedad estime compatible con la razón ${ }^{19}$. Esos jueces, que como cualquier otro ser humano no pueden entenderse ya en posesión de ningún privilegiado acceso a la verdad moral o a valores de validez absoluta e intemporal, tendrán que justificar ante la sociedad sus opciones como compatibles con la razón. Con ello llegamos a la idea de justificación argumentativa de la decisión valorativa, concepto fundamental en la teoría de Perelman y en las teorias de la argumentación juridica en general.

Para Perelman, razonamiento práctico es "aquel que justifica una decisión», y el ejemplo prototípico de tal clase de razonamiento seria el de la motivación de las sentencias por el juez ${ }^{20}$. En relación con esta importancia de la justificación intersubjetiva de las decisiones como razona- bles aparece la importancia de la retórica en Perelman. Si la razonabilidad de la decisión no sc mucstra como evidente o necesaria, sino que ha de ser justificada, argumentada, el instrumento adecuado al efecto será la retórica. «La retórica, tal como la concebimos - dice Perelman--, consistirá en un estudio de los medios de argumentación que permiten obtener $o$ acrecentar la adhesión de los espíritus a las tesis que se someten a su asentimienlow ${ }^{21}$. De ahí que realísticamente diga Perelman que «motivar un juicio, es decir, justificar10 , no es fundamentarlo de modo impersonal y, por así decir, demostrativom, sino que «es persuadir a un auditorio, al que se ha de conocer, de que la decisión está de acuerdo con sus exigencias», para lo cual la motivación se adaptará al tipo de auditorio al que se pretende persuadir ${ }^{22}$, ya que «toda argumentación se desarrolla en función de un auditorions. ${ }^{23}$. Pero con estos planteamientos se llega a uno de los dilemas de la doctrina perelmaniana: el de la tensión entre eficacia y racionalidad de la justificación.

En Perelman el consenso aparece claramente indicado como criterio último con el que juzgar acerca de la razonabilidad o no de la decisión y las valoraciones que la provocan. Si se han de justificar las decisiones es porque se presupone que la decisión puede y debe encontrar el acuerdo de la sociedad o la parte de la misma de que se trate. Ahora bien, tenemos, por un lado, que la «nueva retórica» de Perelman estudia «los medios discursivos para obtener la adhesión de los espíritus» ${ }^{24}$, y que esa adhesión puede venir determinada o influida por la habilidad en el manejo de la retórica por parte de quien justifica la decisión. Pero cuanto más se nos muestre como manipulado o inducido cse consenso social en tomo a la decisión tanto menos se podrá presentar el dato del consenso como indicio de la racionalidad de la decisión. 
Trata de salvar este dilema con su conocida distinción entre persuadir y convencer, por un lado, $y$ auditorio particular $y$ auditorio universal, por otro. Persuasiva es la argumentación que «sólo pretende valer para un auditorio particular», mientras que convincente es aquella que se pretende apta para «obtener la adhesión de todo ser de razón» ${ }^{25}$, es decir, del «auditorio universal». Solamente esta argumentación que trata de lograr la convicción del auditorio universal puede calificarse como racional. La otra tendrá un valor puramente instrumental, ligado a la defensa de intereses particulares, ideologias, etc. $* \mathrm{El}$ discurso dirigido a un auditorio particular tiende a persuadir, mientras que el que se dirige al auditorio universal tiende a convencer», $\mathrm{Y}$ añade Perelman que «un discurso convincente es aquel en el que las premisas y los argumentos son universalizables, es decir, aceptables, en principio, para todos los miembros del auditorio universals ${ }^{26}$.

En el fondo, la racionalidad de la argumentación no vendría dada por el hecho de que efectivamente alcance el consenso que pretende, sino por el hecho de pretender ese consenso de una determinada manera, apelando a la razón común entre las personas y no a resortes irracionales ${ }^{27}$. El prototipo de argumentación racional sería la argumentación filosófica, que busca justificar tesis aceptables para todo ser racional. Y Perelman plantea su doctrina, la teoría de la argumentación o nueva retótica, como abarcadora por igual de «todo el campo de la argumentación tendente convencer o a persuadir, cualquiera que sea el auditorio al que se dirija y cualquiera que sea la materia de la que se trates, y tanto la lógica filosófica como la lógica jurídica (en el sentido en que Perelman habla de lógica no como lógica formal, sino como tipo de pensamiento racional) «no serían sino aplicaciones particulares de la nueva retórica al derecho y a la filosofía ${ }^{2 x}$.
¿Pero de qué tipo sería la argumentación jurídica, tal como se contiene, por ejemplo, en la motivación de una sentencia judicial? El mismo Perelman admite que la argumentación jurídica difiere, debido a los condicionamientos prácticos a que está sometida, del tipo de argumentación racional encamado por la filosofia ${ }^{29}$. La argumentación jurídica se puede mencionar incluso como ejemplo de justificación dirigida a un auditorio particular ${ }^{30}$. De ahi que el derecho y su racionalidad posible aparezcan en Perelman en têrminos un tanto equívocos: «el derecho es simultáneamente acto de autoridad y obra de razón y de persuasión» ${ }^{31}$. El elemento propiamente retórico o de manejo de un instrumental, apto para condicionar la adhesión del auditorio de que se trate, estaría en la argumentación juridica en tensión con el elemento de racionalidad, que se daría únicamente si se argumentara con vistas a obtener el acuerdo hipotético de todos sobre la base de la ponderación no manipulada de los argumentos. Pero con esto nos encontrariamos ante el dilema de si en el manejo práctico del derecho y en la justificación de sus decisiones se da realmente más relevancia al dato de la eficacia $o$ al elemento de la razón.

Perelman mismo describe la argumentación eficaz como aquella que consigue del auditorio una adhesión suficientemente intensa como para mover a la acción en el sentidu deseado ${ }^{32}$. Y, naturalmente, una argumentación como la juridica, tan ligada a consecuencias prácticas, no podrá renunciar a esa dimensión de eficacia práctica, por lo que tendrá un ineludible componente persuasivo $y$ jugará en ella un papel el elemento *irracional» ${ }^{33}$. Y el propio Perelman se interroga sobre cuál será el criterio para medir la mayor o menor racionalidad de esa argumentación que necesariamente ha de pretenderse eficaz y no meramente racional, a lo cual responderá que serán los propios planteamientos y el propio enfoque del argumen- 
tar (según que se haga con las miras puestas en la persuasión de un auditorio particular o en la convicción del auditorio universal) el críterio que nos permitirá juzgar de su grado de racionalidad ${ }^{34}$. Pcro con ello estamos razonando de modo circular, pues lo que nos estábamos preguntando es cómo se mide la racionalidad de una argumentación, como la jurídica, que por imperativos prácticos tiende precisamente, al menos en parte, a la persuasión de un auditorio particular. $Y$ poco se aclara al respecto si se hace del tema una mera cuestión de intenciones, como cuando Perelman afirma que la orientación al auditorio universal es propia de los espíritus más racionalistas y honestos ${ }^{35}$, o que la clave está en «pretender» la universalidad de las premisas ${ }^{36} \mathrm{y}$ en no tratar de justificar premisas que se saben no universalizables e interesadas, o cuando se interpreta su pensamiento en el sentido de que el phronimos o prudent es el argumentador capaz de ver lo universal en lo particular ${ }^{37}$.

$Y$ tampoco aclaran más la cuestión sus puntualizaciones sobre la naturaleza del auditorio universal. Éste sería en realidad una "ficción" ${ }^{38}$. que el argumentante se representa como encarnación del conjunto imaginario de todos los seres racionales, y cl tipo de acuerdo al que tiende la argumentación a él orientada no se mide en términos de ningún consenso efectivo o empírico, sino de cuna universalidad y una unanimidad que el orador se representa, del acuerdo de un auditorio que debería ser universal» ${ }^{39}$. Por tanto, la remisión al auditorio universal no sirve como baremo que ofrezca una referencia firme y constatable, sino que se trata de una pura construcción ideal, de una idea regulativa a la que tendencialmente se acercarán ciertas elaboraciones argumentativas en razón del grado de generalidad con que sus premisas se formulen y sin que el supuesto acuerdo universal del que serían susceptibles pueda manifestarse en ninguna forma de consenso efectivamente mensurable, pues «el acuerdo de un auditorio universal no es una cuestión de hecho, sino de derechos ${ }^{40}$.

Vemos cómo Perelman describe el componente prioritariamente retórico de la argumentación jurídica, pero no se resigna a admitir que el mismo esté al servicio de las contingencias de la práctica y de los intereses en litigio, no reconoce que la racionalidad de esa argumentación sea meramente funcional o instrumental. $Y$ de ahi la peculiar dualidad de la obra perelmaniana ${ }^{41}$, en la que se explican con enorme rigor y acierto las formas de uso de los recursos retóricos y, al mismo tiempo, parece darse por sentado que una argumentación que haga uso preferente de esas herramientas retóricas, que sirven para mover al auditorio, será fundamentalmente irracional.

\section{Habermas como inspirador de la teoria de la argumentación jurídica}

En esa pretensión de Perelman de dar, a pesar de todo, indicaciones para distinguir la argumentación racional de la que no lo sea se diferenciaría, por ejemplo, de los planteamientos coetáneos de la tópica jurídica. Y, por otro lado, será precisamente en la concreción, desarrollo y fundamentación de los criterios normativos de racionalidad donde las posteriores teorías de la argumentación tratarán de ir más allá de Perelman. Apuntemos muy brevemente cómo las más recientes teorías de la argumentación buscan un sustento más elaborado para la racionalidad jurídica como racionalidad consensual y discursiva. Como inspiración fundamental de la más representativa de las actuales teorías de la argumentación jurídica, la de Robert Alexy ${ }^{42}$, está la ética discursiva de Habermas. También para Habermas, como para Perelman, la argumentación racional es aquella que maneja argumentos capaces de convencer a todo interlocutor racional que pudiese participar en la discusión. 
Ahora bien, la fundamentación de ese postulado de universalización de los argumentos, emparentado con el imperativo categórico kantiano (al igual que el concepto de argumentación ante el auditorio universal de Perelman), recibe en Habermas un ulterior fundamento que no estaba presente en Perelman, En efecto, los presupuestos de la argumentación racional, sintetizados en el principio de universalización, se darían en toda argumentación como condición de posibilidad y de sentido del lenguaje mismo. El argumentar buscando el consenso libre de todo ser racional, buscando to que Perelman llamaba convencer y no meramente persuadir, ya no es un postulado moral producido sin más por la conciencia individual ni una simple recomendación práctica para una mejor convivencia, sino un presupuesto que damos por válido y sentado cada vez que nos comunicamos, de forma que quien mediante la argumentación no busca el libre acuerdo sino la manipulación, quien no defiende intereses generalizables, sino egoístas, estaría contradiciendo tales presupuestos de su propia actividad argumentativa e incurriendo en contradicción pragmática $o$ realizativa. Para Habermas la existencia de sociedad es posible gracias a que es factible el entendimiento entre los sujetos a travếs del lenguaje. Al servirse del lenguaje el individuo participa necesariamente de la perspectiva social, sale «de la lógica egocéntrica» ${ }^{43}$. La comunicación lingüística sólo tiene sentido y razón de ser en cuanto orientada al entendimiento con el otro, lo cual hace que quien se comunica no pueda sustraerse a las condiciones de racionalidad inmanentes a la acción comunicativa. Por tanto, toda acción lingüistica es idealmente una «acción orientada al entendimiento», y quien actúa en sociedad y se comunica no puede sustraerse a los presupuestos de dicha comunicación, al «carácter inexcusable de aquellos presupuestos universales que condicio- nan siempre nuestra práctica comunicativa cotidiana y que no podemos elegirs ${ }^{44}$.

Puesto que toda comunicación tiende al entendimiento como su telos inmanente ${ }^{45}$, tenemos que toda comunicación busca en última instancia el acuerdo. Quien habla aspira a validez general para su emisión, busca que todas las personas reconocidas como interlocutores válidos la admitan como adecuada. Así pues, cl lenguaje es, como medio de orden social, la alternativa a la mera violencia entre seres asociales.

Lo anterior implica que toda emisión comunicativa llcva implícita una pretensión de validez intersubjetiva, que «al lenguaje le es inmanente la dimensión de la validez» y que «la orientación a pretensiones de validez pertenece a las condiciones pragmáticas de posibilidad del entendimiento* ${ }^{46}$. Quien realiza un acto de habla está haciendo a sus interlocutores una oferta de entendimiento sobre algo en el mundo objetivo, en la sociedad o en si mismo, y esa oferta envuelve una pretensión de ser aceptada, de generar acuerdo sobre su corrección a la luz del mundo objetivo, de la sociedad o de la personalidad del sujeto. Y el interlocutor, ante esa oferta, está racionalmente forzado a tomar postura en sentido afirmativo o negativo, admitiendo la validez o cuestionándola. En caso de desacuerdo inicial sobre la validez de la emisión los interlocutores estarian forzados, por razón de la propia racionalidad inmanente a la comunicación, a buscar el restablecimiento del acuerdo mediante la aportación de razones o argumentos que permitan un nuevo consenso en tomo a las razones mejores. En palabras de Habermas, "con una pretensión de validez un hablante apela a un potencial de razones que, llegado ol caso, podría sacar a la palestra en favor de csa pretensión ${ }^{4}$. En última instancia, hablar es comprometerse en la generación de expectativas y entenderse es compartir expectativas, 
expectativas que, en cuanto compartidas, hacen posible la coordinación social.

Así pues, toda emisión comunicativa aspira tendencialmente a un entendimiento pleno en torno a un acuerdo de alcance universal. Una emisión comunicativa que responda a la racionalidad última del lenguaje no pretenderá un acuerdo vinculado a razones relativas, o engañosas, 0 aceptables sólo para algunos, Cuando no ocurre así, cuando a sabiendas se busca un consenso no libre, cuando se manipulan las razones y se instrumentaliza a los interlocutores, se está llevando a cabo una utilización parasitaria del lenguaje.

Para el sujeto racional se sigue una cierta compulsión intelectual a ser congruente con los presupuestos o condiciones de posibilidad de los instrumentos comunicativos de que hace uso para vivir en sociedad. Habermas explica eso que llama también «el fundamento normativo de la comunicación lingüística» diciendo que quien toma parte en un discurso da por sentados, «al menos implícitamente, determinados presupuestos, que son los únicos que permiten el acuerdo: así, los presupuestos de que las proposiciones verdaderas son preferibles a las falsas y que las normas justas (esto es: susceptibles de justificación) son preferibles a las injustas» ${ }^{48}$.

Trasladado a Perclman ese modelo, tendríamos que se restablecería la unidad entre la retórica como técnica de persuasión y como argumentación racional: a ambos usos de la comunicación subyacería idéntica exigencia de racionalidad y búsqueda de consenso libre, pero mientras que el primero sería un ejemplo de racionalidad instrumental, contradictoria con las condiciones de sentido del propio lenguaje que utiliza, un uso parasitario del lenguaje y la comunicación, el segundo sería un supuesto de acción comunicativa, de ejercicio coherente de la comunicación.

$\mathrm{Y}$ el referente ideal, que en Perelman es el auditorio universal, aparece en Habermas como «comunidad ideal de diá- logo». Pero en este último caso hay una mayor elaboración. La comunidad ideal de diálogo ya no es la simple agregación imaginaria de todos los scres racionales, sino aquella situación ideal en la cual se cumpliesen plenamente los presupuestos y reglas implícitos en la comunicación, en que el procedimiento argumentativo racional sc realizase perfectamente. Con ello, los sujetos capaces de lenguaje y colocados en esa situación carecerían de toda traba, coacción o manipulación que les impidicra percibir su interés y ponerse de acuerdo y consentir todos por igual sobre las decisiones acordes con el interés general. En Perelman la intersubjetividad como clave de la racionalidad es un postulado de la conciencia individual, un imperativo de conciencia; en Habermas la racionalidad como orientación al consenso intersubjetivo es presupuesto trascendental de la praxis lingüistica, condición de posibilidad del lenguaje.

Vemos cómo el paso de Perelman a Habermas supone el trắnsito de fundamentar el principio de universalización, en cuanto núcleo de la racionalidad práctica, como postulado de la conciencia individual ${ }^{49}$ a presupuesto inmanente a la comunicación intersubjetiva, al lenguaje.

¿Qué queda de la relación entre retórica y derecho? Hemos visto que la teoría de la argumentación jurídica arranca de considerar esencial en el derecho y en su legitímación una cierta praxis retórica, y que, al mismo tiempo, trata de huir de un planteamiento propiamente descriptivo de los recursos retóricos y su uso en el derecho para reglamentar ese discurso a fin de alcanzar un parámetro con el que medir la mayor o menor racionalidad de sus resultados. Las reglas que enumera Alexy son el mejor ejemplo de esto ${ }^{50}$. Con ello la teoría de la argumentación acaba siendo una teoría formal y procedimental de la racionalidad jurídica: argumentación juridica racional es aquella que se desarrolla con respeto de tales reglas ordenadoras del 
discurso, reglas que idealmente garantizan que el resultado final podrá ser consentido por todo interlocutor imparcial, por representar el interés de todo y no una postura egoísta o puramente individual.

Parece, pues, que por la retórica (y la tópica) se ha pasado únicamente como estación en el camino hacia una doctrina más «filosófica». Sin embargo, han quedado huellas y vías permanentes. Hoy ya es habitual considerar los tradicionales recursos metodológicos (los cánones de la interpretación jurídica, por ejemplo) como argumentos que se usan en el seno de un debate buscando la convicción o persuasiôn. Y existen obras importantes que analizan desde un punto de vista similar la utilización que de tales recursos hacen, por ejemplo, los tribunales de justicia ${ }^{51}$. Pero en ese tipo de análisis queda mucho por hacer y tendría pleno sentido la colaboración a tal fin de teóricos del derecho y del lenguaje y la comunicación 52 .

Por otro lado, el estudio del derecho en clave linguística y comunicativa viene dando lugar en los últimos años a dos enfoques que no se centran en la retórica en sentido estricto, pero que abren campos en los que la retórica jurídica puede ubicarsc. Nos referimos a la scmiótica jurídica y a la concepción «narrativa» del derecho. Esta última, bajo distintas inspiraciones, entre la que se cuenta muy relevantemente la teoría de la deconstrucción de Derrida, lee los textos jurídicos, legales, jurispru- denciales y dogmáticos tratando de mostrar de qué modo en ellos se «construye» un cierto mundo imaginario desde el que se opera efectivamente sobre la realidad ${ }^{53}$, generalmente al servicio de poderes e intereses que se camuflan bajo toda una parafernalia conceptual. El movimiento norteamericano de Critical Legal Studies, en su heterogeneidad, refleja en buena medida este planteamiento ${ }^{54}$.

En cuanto a la semiótica jurídica, responde al esfuerzo de una serie de juristas (B. Jackson, E. Landowski, D. Carzo, R. Carrion-Wan, R. Kelvelson ${ }^{55}$, etc.) por trasladar el análisis semiótico al mundo jurídico, pero no sólo como análisis de textos, sino también y muy especialmente como análisis de interacciones sociales, con una fuerte presencia de la dimensión pragmática, atendiendo a los múltiples factores que inciden en la adscripción de «significación» al lenguaje jurídico y a los actos que desde él se califican ${ }^{56}$. Aunque crítico con algunos planteamientos de la semiótica jurídica, $y$ desde luego con la nueva rctórica de Pcrclman, posiblemente es Peter Goodrich el autor que mejor ha planteado una lectura retórica del derecho, entendiéndolo como «discurso social» ${ }^{5}$. Un muy completo análisis tanto de textos jurídicos como de estructuras retóricas de sentencias, desde el punto de vista de lo que denomina «semiótica retórica», lo ofrece Waldemar Schreckenberger en su Semiótica del discurso jurídico ${ }^{58}$.

\footnotetext{
1 Ulfrid Neumann sostiene que la teoria de la argumentación jurídica señala un tercer camino entre decisionismo y determinismo jurídico, entre la idea de que la aplicación del derecho está presidida por la libertad decisoria del jucz y la idea de que la decisión de éste está plenamente determinada por el ordenamiento (U. Neumanת, Jurstische Argumentationsichre, Darmstadt, Wissenschaftliche Buchgesellschait, 1986, p. 2).
}

${ }^{2}$ Cfr. O. Ballweg, sPhronetik, Semiotik und Rhe" torikm, еп Rhetorische Rechtstheoric: zum 75. Geburtstag won Theodor Viehweg, Freiburg i.Br.München, Alber, 1982, pp. 44-45; «La rationalite prudentielle», en Archives de Philosophie du Droit, 23, 1978, p. 260.

${ }^{3} \mathrm{Th}$. Viebwcg, Topik und Jurispmudenz, München, Beck, 5. ed, 1974, p. 96. Hay traducción castellana de la segunda edición, Tópica y jurisprudencia, Madrid, Taurus, 1964. Para un estudio en detale de la obra 
de Viehweg puede verse J. A. García Amado, Teorias de la tópica juridica, Madrid, Civitas, 1988, donde se analiza tambićn la contemporánea rehabilitación de la tópica en otras disciplinas y se repasa brevemente su significado en la antigùedad.

* Ibid., p. 31. Por "problema» entiende Viehweg "toda cuestión que aparentemente admite más de una respuesta y que necesariamente presupone una comprensión provisional, a partir de la cual aparece como cucstión a considerar serianente y para la que se busca precisamente una respuesta como solución" (ibid, p. 32).

s Como ejemplos de tópicos jurídicos actuales cita Viehweg únicamente la buena fe, el interés, la protección de la confianza y los conceptos juridicos en general (Th. Viehweg, Topik und Jurisprudenz, cit., p. 95). La más amplia enumeración de tópicos juridicos se contiene en G. Struck, Topische Jurisprudenz, Frankfurt M., Athenäum, 1971, pp. 20-34. Esos mismos tópicos son sistematizados en Ch. Perelman, La logica juridica y la nueva retónica, Madrid, Civitas, 1979 , pp. 120-128.

6 Cfr. R. Alexy, Theorie der juristischen Argumentation, Frankfurt M, Suhrkamp, 1978, p. 42.

'W. Hassemer, «uristische Argumentationstheorie und juristische Didaktikn, en Jahrbuch für Rechtssoziologie und Rechtstherie, 2, 1972, p. 47.

${ }^{8}$ L. Mengoni, Dirito e valori, Bologna, Il Mulino, 1985 , p. 42.

Ch. Perelman, Justice et raison, Bruxelles, Presses Universitaites, 1963, p. 75 .

19 Ch. Perclman, Rhétorique et philosophie, Paris, Presses Universitaires de France, 1952, p. 160.

$" \mathrm{Ch}$. Perclman, Droit, morale ef philosophie, Paris, LGDI, 2" ed., 1976, p. 48.

$12 \mathrm{Ch}$. Perelman, Rhétorique et philosophie, cit. pp. 12 y $s \mathrm{~s}$.

" Ch. Perelman, Ethique et Droit, Bruxelles, Editions de L'Université de Bruxelles, 1990, p. 674.

${ }^{14}$ Ch. Perelman, Ethique et Droit, cit., p. 292.

is Mid, p. 516 .

16 Ibid., p. 675 .

17 Ibid., p. 327.

1 Cfr. Ibid., pp. 431 y s\$., pp. $520-521$.

"Cir. lbid., p. 545, 672.

a kid, pp. 333-334. Pero más allá de ese cjemplo concreto wla argumentación interviene en todos los casos en que las personas deben tomar decisjones, realizar elecciones reflexivas, cada vez que tienen que deliberar o disculir, criticar o justificars (Ch. Perelman, Logique et argumentation, cit. pp. 84-85).

${ }^{21}$ Ch. Perelman y L. Obrechts-Tyteca, Rhétorique et Philasophie, cit., p. 125.

${ }^{2}$ Ch. Perelman, Ethique et Droit, cit, p. 679.

"Ch. Perelman y L. Olbrechis-Tyteca, Traitế de l'Argumentation. La Nouvelle Rhétorique, Bruxelles, Editions de I'Université de Bruxelles, 3." ed., 1970, p. 8 (existe traducción castellana de esta obra: Tratado de la argumentación. La nueva retórica, Madrid, Gredos, 1989). Por auditorio se enticnde eel conjunto de todos aquellos sobre los que el orador quiere influir mediante su argumentación (ibid., p. 25).

${ }^{24}$ Ch. Perelman y L. Otbrechts-Tyteca, Traité de I'Argumentotion, cit, p. 10 .

${ }^{25}$ Ibid., p. 22.

*h Ch. Perelman, Lempire shétorique. Rhêtorique et argumentation, Paris, J. Vrin, 1977, p. 31.

${ }^{27}$ Crr. Ch. Perelman y L. Olbrechts-Tyteca, Rhetorique et Philosophie, cit., pp. 110 y ss.

25 Ch. Perelman, L'empire phérorique, cit., p. 19.

* Ch. Perelman, La lógica juridica y la nueva retórica, Madrid, Civitas, 1979 (trad, de L. Diez-Picazo), pp. 162 y ss.

so Ch. Perelman y L. Obrechts-Tyteca, Rhéforique et Philosophie, cit., p. 130.

31 Ch. Perelman, Ethique et Droit, cit., p. 679.

32 Ch. Perelman y L. Olbrechts Tyteca, Trate de I'Argamentation, cit., p. 59.

3 Cfr. Ch. Perelman y L. Olbrechts-Tyteca, Ritetorique et Philosophite, cit., p. 34.

34 Ibid., pp. 38-39.

3s Mid, p. 39 .

* Ibid. P. 119. Desde este planteamiento no es sorprendente que Perelman acabe manifestando la proximidad de su molelo de argumentación orientada al auditorio universal, al concepto kantiano de imperativo categórico (ibid). «Es evidente -atiade Perelmanque este auditorio universal al que cada pensador racional se dirige no es más que una creación de su espiritu: en función de este último, de su informacionn, de la concepción que posea acerca de los valores que se denominan universales, está históricamente y socialmente determinado y está situado en el contexto de una cultura y varía con esta últimas (ibid., p. 120).

37 G. Haarscher, «Après Perelman», in Justice et Argumentation, Bruxelles, Etidions de l'Université de Bruxelles, 1986, p. 224.

${ }^{38} \mathrm{Ch}$. Perclman y L. Olbrechts-Tyteca, Rhétorique et Philosophie, cit., p. 39.

39 Ch. Perelman y L. Olbrechts-Tyteca, Traite de I'Argumentation, cit., p. 41.

4hid, p. 158 .

41 Fsa dualidad estaria ya contenida también en la retórica de Aristóteles. Vid Aristóteles, Topicos, VIII 160b, 161a, 16lb; Retorica, I 1355b 5-10, 1404a 1-10. Por eso se ha hablado del «dilema etico de toda retotica” (W. Eisenhut, Einfuhrng in die antike Rhetorik wnd ihre Geschichte, Darmstadt, Wissenschaftliche Buchgesellschaft, 1982, p. 32).

42 De la obra crucial de Alexy en este tema, Theoric der juristischen Argumentation, hay traduccion casteIlana, Teoria de la angumentación jurídica, Madrid, Centro de Estudios Constitucionales, 1989, Una magnífica exposición de las actuales teorias de la argumentación jurídica, incluyendo a Perelman, Viebweg, Alexy y otros autores aquí no exaninados, como Toulmin y MacCormick, puede verse en M. Atienza Las razones del Derecho. Teoras de la argumentación jurfdica, Madrid, Centro de Estudios Constitucionales, 1993. 
4.5 J. Habermas, pensamiento postmetafisico, Madrid, Taurus, 1990 , p. 85.

4 J. Habermas, Moralbewusstsein und kommunikatives Handeln, Frankfurt M., Sthrkamp, 1983, p, 141.

45 J. Habermas, El discurso filosófico de la modernidad, Madrid, Taurus, $1989, \mathrm{p} 369$.

40 J. Habermas, Entgegnung", en A. Honneth y H. Joas (eds.) Kommunikatives Handeln, Frankfurt M. Suhrkamp, 1988, p. 360.

") J. Habermas, Pensamiento postmetafisico, cit. p. 84

* J. Habermas, La reconstrucción del materialismo histórico, Madrid, Taurus, 1981, p. 179.

4 Insistamos en que, frente a la fundamentución intersubjetivista que Habermas trata de proporcionar de ese modo, Perelman da de la racionalidad de la argumentación un fundamento sítuado en la conciencia individual, como el imperativo categórico de Kant, al que expresanente remite Perelman: «una tal argumentación - racional, dirigida al auditorio universal- se somete a las exigencias del imperativo categórico (...) Se trata en cste caso, cyidentementc, de una hipotesis del orador sobre lo que merecería el acuerdo de este auditorio» (Ch. Perelman, Logique el agumentation, cit., p. 105). «En efecto, cada uno se forma una idea de este auditorio universal a partit de lo que considera como válido para él mismo, debichdo imponerse igual. mente a todos las razones de esta validez" (ibid., p. 106). "Esta universalidad, no fundada ni sobre la necesidad ni sobre la evidencia, no puede manifestar más que una intención, la intención de superar los puntos de vista parciales y particularess (ibid., p. 146).

s0 La tabla de dichas reglas puede verse en el apéndice a R. Alexy, Theorie der juristischen Argumentation, cit. En la traducción castellana se encuentran en las pp. 283-287.
\$1 F. J. Ezquiaga Ganuzas, La argumentación en la justicia constitucional española, Onati, Instituto Vasco de Administración Pública, 1987.

52 Buenos ejemplos de analisis de documentos jurí dicos y de procesos juridicos pueden verse, respectivamente, en Th. M. Seibert, Aktenanalysen. Zur Schrifform juristischer Deutungen, Tübingen, Gunter Narr, 1981, y L. Hoffmann (ed.), Rechtsdiskurse. Untersuchungen zur Kommunikation in Gerichtsverfahren, Tübingen, Gunter Nart, 1989.

${ }^{53}$ En España una aproximación en clave anarrativa» a la explicación de múltiples aspectos del fenómeno jurídico puede verse en las obras de J. Calvo González, Comunidad juridica y experiencia interpretatina, Barcelona, Ariel, 1992; El discurso de los hechos: narrativismo en la interpretacion operatwa, Madrid, "Tecnos, 1993; Derecho y maracion, Barcelona, Ariel, 1996.

¿4 Cfr. J. A. Pêrez Lledó, El movimiento "Critical Legal Studies", Madrid, Tecnos, 1996.

"s Algunas indicaciones bibliograficas: B. S. Jackson, Semiotics and Legal Theory, Londres, Routledge \& Kcgan Paul, 1985; Law, Fact and Narative Coherence, Merseyside, Deborah Charles, 1988; E. Landowski, La société réfléchie, Paris, Editions du Seuil, 1989; D. Carzo, I segni del potere, Milano, Giuffrè, 1981; R. Carrion-Wan, wemiôtica juridica", en D. Carzo, y B. S. Jackson (cds.), Semiotics, Law and Social Science, Roma, Gangemi, 1985, pp. 11-67. R. Kevelson, The Law as a System of Signs, New York, Plenum Press, 1988.

\$6 Vid, E Landowski, La société réfléchie, cit., pp. 75 yss.

\$7 Vid. P. Goodrich, Legal discourse. Studies in Linguistics, Rhetoric and Legat Analysis, Londres, MacMiIlan, 1987, especialmente pp. 85 y ss.

* México, UNAM, 1987. 